\title{
THE DETECTION OF DEFECTS IN GRP LATTICE STRUCTURES BY VIBRATION MEASUREMENTS
}

R D Adams ${ }^{*}, \mathrm{~J}$ M W Brownjohn ${ }^{* *}, \mathrm{P}$ Cawley ${ }^{* * *}$

*Professor, Department of Mechanical Engineering, University of Bristol

*** Research Fellow, Department of Civil Engineering, University of Bristol

*** Senior Lecturer, Department of Mechanical Engineering, Imperial College

\section{SUMMARY}

For certain types of glass-reinforced plastic (GRP) structure, methods of non-destructive testing (NDT) based on the detection of altered or unusual modal properties can be cost effective alternatives to conventional techniques. Changes in natural frequencies and the occurrence of anomalous mode shapes determined from quick and simple measurements were used as indicators of structural damage in a series of tests on GRP space frame lattice structures for which other forms of NDT were not appropriate.

The modal analysis techniques used to identify a set of modal characteristics to be used as indicators of damage, and the methods of identifying significant changes in these characteristics are described. The methods were able to detect various forms of damage such as severed members, delamination and crushing. It is concluded that a combination of visual and modal checks would form an effective means of detecting flawed structures.

\section{INTRODUCTION}

In applications where there is a requirement for rigid lightweight structures that have high electrical resistance and do not corrode, space-frame lattices made from glass reinforced plastic (GRP) are particularly suitable. Figure 1 shows an example of such a structure which has been the subject of a study into the application of structural dynamics to quality control. This particular structure is used as a beam element in portal frames such as those used for carrying overhead power lines for electrified railways, although there are many other applications.

Because the beams are often used in safety-critical situations, effective means of NDT are required. Defects that might be found in these structures include delamination of fibres and resin caused by crushing or impact, resulting in a significant reduction in load bearing capacity. Conventional non-destructive testing methods either cannot be used or are prohibitively expensive for this structure; $X$-ray and ultrasound techniques would be costly and laborious and the results difficult to interpret; eddy current and magnetic flaw detection methods will of course not work and dye-penetrants will only 
show surface cracks. Novel techniques are therefore required and vibration measurements are potentially very attractive since they are quick and simple to apply. In order to be useful in quality control (QC) of mass-produced structures of this type, techniques relying on modal properties would have to identify changes of these properties with respect to a set of 'baseline' modes established from testing a representative undamaged sample. Methods of identifying these changes need to account for the skill of the NDT operator and reliable methods of extracting the relevant data from the 'noise' of all effects other than damage are required.

\section{MODAL METHODS OF NON-DESTRUCTIVE TESTING}

NDT techniques relying on the modal behaviour of vibrating structures ${ }^{1}$ can be divided broadly into four categories, according to whether the measured property that is affected by defects is a global (e.g. mode shapes) or a local phenomenon (e.g. local heating effects) and to how the excitation is distributed. Examples are:

1) Determination of global response from measurements and excitation at a single point. Examples are assessment of foundation pile integrity by impact testing ${ }^{2}$ and techniques including and derived from wheel tapping ${ }^{3}$.

2) Multiple measurements of local response over the structure due to excitation at a single point. Examples are laser holography and vibrothermography ${ }^{4}$.

3) Measurements of local response at all points on the structure due to excitation at the same points, for example the coin tap test ${ }^{5}$ used with laminated and honeycomb structures.

4) Measurements of global response at a selection of points due to multi-point excitation, as in a modal survey. Much research effort ${ }^{6}$ has been applied to the development of techniques for systematic comparison of such measurements with modal data generated from an analytical model in order to locate deficiencies in an analytical model, which is equivalent to locating damage if the model is correct and the structure is not.

Category one techniques, relying on a single measurement and subsequent signal processing, are the simplest to perform but tend to be insensitive to small, localised defects. However they provide a result very quickly and are therefore attractive in applications where very small defects do not need to be detected. For example, in piles the damage can be cracking or local changes in cross sectional area which affect the transmission and reflection of transient stress waves. Category three techniques are also straightforward but rather time-consuming since the whole surface of the structure has to be scanned by a transducer. Category two and four techniques are 
more common in aerospace applications where the expense of sophisticated measurement or processing equipment can be justified.

Reference 7 provides a review and bibliography of techniques for assessing of structural integrity from dynamic measurements; it is category one techniques of the type developed for integrity monitoring of buildings ${ }^{8}$, bridges ${ }^{9}$ and offshore structures ${ }^{10}$ that are the concern of this paper.

\section{MODAL METHODS OF QUALITY CONTROL}

Where category one techniques are used to check the integrity of a structure continuously or at regular intervals, they take the form of checking a form of dynamic 'signature' against that of the original undamaged structure. This signature can, for example, be the frequency spectrum of response to random or transient excitation or the random decrement signal ${ }^{\mathbf{1 1}}$.

When using such techniques for the quality control of production batches, the signature of the undamaged structure is not known exactly and it is only possible to make comparisons with a 'baseline' derived from measurements on a sample of typical undamaged structures.

One example of modal quality control is given by Cawley ${ }^{12}$, where sample specimens are hit by a light hammer and the transient response is displayed as a frequency spectrum in which shifts of natural frequencies indicate defects. This technique requires either a trained operator with prior information about the expected values of frequencies and the ability to judge a significant change or software that is capable of identifying the changes automatically. This software would require someone experienced in structural dynamics to set up parameters for each different type of structure, after which the processing and decision making for each sample could be done by a 'black box' of signal processing software to provide a 'pass', 'fail' or 'don't know' result in a simple and quick modal QC method.

Such a black box processor could use techniques of pattern recognition for which a prerequisite is a knowledge base of the dynamic behaviour of a range of sample structures. One application of pattern recognition techniques to transient time histories recorded in the impact testing of piles ${ }^{13}$ has so far shown an $85 \%$ success rate in automatic identification of defects. This technique is being developed and applied to other structures.

For an NDT technique based on measuring changes in modal properties due to damage, the setting up phase would proceed as follows:

1) Identify a set of modes of vibration in terms of natural frequencies and mode shapes for a batch of test specimens. 
2) Select a subset of well-defined and easily measured modes.

3) Determine the sensitivity of the modal parameters to test conditions.

4) Use transient testing to determine the natural frequencies for these modes as baseline data.

5) Inflict controlled damage of the type likely to be found in practice in the structures.

6) Re-test the damaged beams under typical quality control conditions to obtain the new natural frequencies.

7) For each specimen, compare its post-damage response with its pre-damage response and hence determine the types and extent of damage that result in perceptible changes.

8) Compare the response for each specimen with baseline data using simple numerical techniques or more advanced pattern recognition methods, assessing the success of the methods in identifying particular types of damage.

9) Choose appropriate pass/fail thresholds for the type and size of defect which must be detected in production batches.

The procedure outlined above was applied to the GRP lattices, initially using measurements of natural frequency and then by using some criteria for highlighting significant changes.

\section{EXPERIMENTAL MODAL ANALYSIS}

Because natural frequencies are simple to measure and can be strongly affected by damage, it was decided to limit the modal analysis to the determination of the natural frequencies for a set of well defined vibration modes and also to monitor the symmetry of the mode shapes.

The modal property to be measured must be influenced as little as possible by variations of testing condition (e.g. mounting, ambient temperature) if small variations due to damage are to be detected. The first exercise in this study was therefore to determine a reliable, repeatable set of vibration modes from a sample set of test specimens by a process of experimental modal analysis.

\section{Test specimens}

Figure 1 shows a typical GRP beam and Fig. 2 shows two views and dimensions of a beam. The beams are manufactured starting from eight precisely located metal fixing bobbins around which the fibres are wound and set in resin. The winding produces four main axial chords approximately $10 \mathrm{~mm}$ in diameter with a pattern of cross braces approximately $5 \mathrm{~mm}$ in diameter repeated 30 times over a $3 \mathrm{~m}$ length; for reference, 
these bracing sections are numbered 1 to 30 from the end labelled $A$ to the end labelled B. Some test specimens were hand wound and others machine wound, some having aluminium bobbins, others steel. The hand-wound structures had an extra brace member at end A only. Table 1 summarises the features of the 12 different test specimens. Despite the differences, for each specimen the orientation of the bobbins gave the beams two longitudinal planes of symmetry; the 'flat' plane (Fig. 2 upper view) containing the bobbin axes, and the 'side' plane (Fig. 2 lower view) containing the bobbin diameters.

\section{Natural frequencies}

The beams were supported on soft foam blocks intended to allow free vibration, and response to light tapping with a hammer was measured with a Bruel and Kjaer piezoelectric accelerometer attached by wax. A Spectral Dynamics SD375 spectrum analyser displayed the auto power spectrum of the transient acceleration response in the range $0-500 \mathrm{~Hz}$.

Because of the bobbin arrangement, the response differed in the flat and side planes and it was necessary to detect modes of vibration in the different planes. Figure 2 shows accelerometer locations (A1,A2,A3) and positions for hitting the beams, for both planes $(\mathrm{H} 1, \mathrm{H} 2)$. The flexural and torsional modes were excited most strongly by tapping at the centre $(\mathrm{H} 2)$ or edge $(\mathrm{H} 1)$ of the cross-section of the beam, respectively. As a check, tests were carried out with the excitation and measurement positions at each end of the beam.

Figure 3 shows typical acceleration auto power spectra for the following test configurations:

a) tap at $\mathrm{H} 2$, measure at $\mathrm{A} 3$, flat plane

b) tap at $\mathrm{H} 1$, measure at A1, flat plane (enhances torsional modes)

c) tap at $\mathrm{H} 2$, measure at $\mathrm{A} 3$, side plane

d) tap at $\mathrm{H} 1$, measure at A1, side plane (enhances torsional modes)

The arrangements for configurations $\mathrm{a}, \mathrm{b}$ and $\mathrm{c}, \mathrm{d}$ are respectively shown in the upper and lower views of Fig. 2.

\section{Mode shape measurement and categorisation}

To obtain the mode shapes characterising the vibration modes at the prominent frequencies marked in the acceleration auto power spectra (Fig. 3), the beams were excited by attaching an electrodynamic shaker to the structure and tuning the driving frequency of the shaker to the resonant frequency of each mode, while measuring the response of two accelerometers, one fixed at one end, and the other held manually against the beam at different locations. The relative phases and amplitudes measured at each location defined the nature of the mode shapes. Figure 4 shows cross sectional 
views of some of the modes mapped out by this means and which were classified according to type and the number of nodal points (points where the vibration amplitude is practically zero):

1) Flexural modes in the 'flat' plane $(\mathrm{FF})$ with the bobbins moving in the direction of their axes of symmetry, designated $1 \mathrm{FF}, 2 \mathrm{FF}, 3 \mathrm{FF}, 4 \mathrm{FF}, 5 \mathrm{FF}$, having $2,3,4,5$, and 6 nodes respectively.

2) Flexural modes in the 'side' plane (FS) with the bobbins moving in the planes of their diameters, designated $1 \mathrm{FS}, 2 \mathrm{FS}, 3 \mathrm{FS}, 4 \mathrm{FS}$, having 2, 3, 4 and 5 nodes respectively.

3) Torsional ( $T$ ) modes with the whole structure rotating, designated $1 \mathrm{~T}, 2 \mathrm{~T}$, $3 \mathrm{~T}$ having 1,2 and 3 nodes respectively.

4) Breathing modes with expansion and contraction of diagonals of a section, but no net translation or rotation, designated $1 \mathrm{NB}, 3 \mathrm{NB}, 4 \mathrm{NB}, 5 \mathrm{NB}, 6 \mathrm{NB}$ having $1,3,4,5$ or 6 nodes respectively. Mode $2 \mathrm{NB}$ was not reliably determined.

5) 'X' modes which involved rotation of the bracing about the axial chords, hinging at the centreline in each face and with no translational movement of the main axial chords. These modes, which occurred above $400 \mathrm{~Hz}$, were not recorded in the initial modal analysis.

6) Local modes where only a small part of the structure participated in the vibrations.

\section{Anomalous modes}

With the strong excitation provided by a shaker, it was possible to identify a number of modes not excited strongly by transient excitation and to clarify some of the behaviour identified from the hammer testing.

The whole range of breathing modes was identified in this way but, for the lower modes with $0-4$ nodes, the frequencies and mode shapes were found to be highly dependent on the position of the exciter. Several X-modes were also identified.

One type of local mode was established where the bracing supporting the bobbins oscillated without appreciable vibration of the main structure. For the structures with aluminium bobbins this mode generally occurred close to the frequency for mode $3 \mathrm{FF}$, resulting in some confusion. The frequencies for $1 \mathrm{~T}$ and $2 \mathrm{FF}$ were often close in these structures, also leading to confusion.

Figure 5 shows some theoretical mode shapes, together with values of experimentally obtained natural frequencies for structure 6 . The theoretical mode shapes were generated using a finite element model with the bobbins idealised as point masses, which was developed to help explain the modal behaviour and to be used in the development of damage location techniques ${ }^{14}$. The modes of Fig. 5 are shown such 
that the plane of vibration of the FF modes nearly coincides with the plane of the page while the motion in the FS modes appears to come out of the page. The displacements are exaggerated for clarity, emphasising some features of the modes such as the increased participation of the bobbin supports in the higher FF modes.

\section{Repeatability and effect of testing conditions}

Several factors are likely to influence the repeatability of the measured natural frequencies. The most obvious influences are the ambient temperature, the method of support and the location and the mass of the test accelerometer.

Measurements with accelerometers of mass $25 \mathrm{~g}$ and $3 \mathrm{~g}$ showed that the measurement position affected the measured natural frequencies for the heavy accelerometer, while for the light accelerometer the effect was negligible. Experiments with different types of support and support position showed that even when using the soft foam blocks of the original test, moving a support from a node to an antinode in the vibration mode could result in a frequency change of up to $4 \%$ for the fundamental flexural modes $1 \mathrm{FF}$ and $1 \mathrm{FS}$, decreasing to $0.1 \%$ for $3 \mathrm{FF}$ and $3 \mathrm{FS}$. Unless great care is taken in using the same mounting arrangements for different tests there could still be some influence for the lowest modes.

To test for repeatability, measurements on structure 7 were made on four separate occasions with all controllable measurement conditions kept constant; the variations in the measured frequency values for each mode (Table 2) were found to be less than $1 \%$.

One parameter likely to affect all the frequencies is temperature, which tends to reduce stiffness (hence natural frequencies) as it increases. It may also increase dimensions slightly, leading to a reduction in natural frequencies, so temperature effects have to be minimised by comparing frequencies obtained at a common temperature.

\section{Choice of modes for NDT}

From the above discussion of the modes, their clarity and strength of excitation, and their degree of sensitivity to testing conditions, a set of 13 modes was chosen to be measured before and after controlled damage:

1FF, 2FF, 3FF, 4FF, 5FF, 1FS, 2FS, 3FS, 4FS, 2T, 3T, 5NB, 6NB.

Because of the possible confusion of $2 \mathrm{FF}, 2 \mathrm{FS}, 3 \mathrm{FF}$ and $3 \mathrm{FS}$ with local and torsional modes, these were excluded, as was mode $6 \mathrm{NB}$ which usually occurred above $500 \mathrm{~Hz}$, resulting in a subset of eight modes being chosen as the most suitable for use in NDT by measuring changes in natural frequency. These were:

1FF, 4FF, 5FF, 1FS, 4FS, 2T, 3T, 5NB. 
These eight modes are clearly defined, strongly excited, unambiguous and all occur within the $0-500 \mathrm{~Hz}$ bandwidth so that only one frequency range of a spectrum analyser needs to be used to determine all the frequencies with adequate resolution.

\section{TEST, DAMAGE AND RETEST}

\section{Baseline data}

Natural frequencies for the set of thirteen modes were obtained for each of the 12 specimens. The frequencies were measured at three temperatures: $10^{\circ}, 20^{\circ}$ and $30^{\circ} \mathrm{C}$ so that for measurements of natural frequency at a given temperature in a structure with possible damage, a corresponding baseline frequency value for the undamaged structure at the same temperature could be obtained by interpolation. The natural frequencies were obtained with a frequency resolution of $0.625 \mathrm{~Hz}$ from the spectra resulting from excitation in the direction likely to give the strongest response, e.g. flat flexural modes were measured from the spectra for the 'tap at $\mathrm{H} 2$, measure at $\mathrm{A} 3$, flat plane' configuration and torsional modes from spectra for the 'tap at $\mathrm{H} 1$, measure at A1, flat/side plane' spectra.

Figure 6 illustrates both the effect of temperature and of slight variations between the structures on the natural frequency values for mode $2 \mathrm{~T}$ in the hand-wound structures $7-12$. In each mode, the change of frequency with temperature is of the order $0.05 \%$ per ${ }^{\circ} \mathrm{C}$. The mean and variation of the 13 natural frequencies across the batch of structures 6-12 are shown in Table 2.

Although structures 1-5 differed from structures 6-12 either by using steel bobbins and/or by being machine wound (Table 1), the variations of frequencies for the same vibration modes are likely to be similar between repeated measurements, and probably less across a batch of structures when they are machine wound.

\section{Damage and retest}

After establishing the baseline data, various forms of damage were inflicted. Table 1 describes the nature of the damage for each structure.

\section{Retest}

The structures were retested using the same simple set of transient response measurements to determine the new natural frequencies for the set of 13 modes, at a temperature of approximately $20^{\circ} \mathrm{C}$ and with a frequency resolution of $0.625 \mathrm{~Hz}$. The measured frequencies were adjusted for the exact temperature values and then systematically compared with the baseline values. 


\section{EVALUATION OF DAMAGE FROM CHANGES IN FREQUENCY}

\section{Changes from original values}

Table 3 shows (in $\mathrm{Hz}$ ) the changes in frequencies after damage, adjusted to account for temperature variation. For structure 2 , the dynamic behaviour had been drastically altered by the complete cut in the chord, with the appearance of a new set of modes not directly comparable with those of the undamaged structure; only three of the original modes remained in this structure.

The first observation is that, for the majority of cases, there was a slight increase in the natural frequencies. This is somewhat surprising, since it was expected that most forms of damage would result in a reduction in stiffness and hence in natural frequencies. The increases were probably due to slightly stiffer rubber mountings being used in the retesting, together with their slightly different positioning. For modes $1 \mathrm{FS}$ and $1 \mathrm{FF}$ the frequencies increased slightly in all the structures; these modes are the ones most affected by conditions of mounting and did not show any frequency changes that correlated with damage. The last two columns in Table 3 show the summed frequency changes expressed in absolute and percentage terms; for the structures with (at worst) slight damage, the absolute sum is positive and between 0 and $10 \mathrm{~Hz}$, indicating the effect of changed measurement conditions.

Based on the frequency change values, the following observations could be made:

a) Structures 2 and 4 with significant decreases in most natural frequencies were suspected of being badly damaged.

b) Structures 3, 7 and 12 with smaller or less consistent decreases were suspected of being damaged.

c) Structures 8 and 9 showed consistent but modest increases in all but one frequency and may have been structurally modified in a way that stiffened the structure.

Comparing these observations with the actual damage listed in Table 1, burning and local building up of a chord section to repair a crack apparently increased stiffness. Complete severance of a member as in structures 2 and 7 had a significant effect but the effect was smaller for a cut brace member than for a cut chord. The local crushing in structure 12 had a significant effect, while little effect was noted for structure 11 , which may not have been seriously damaged by the impacts.

The apparent contradiction that a $1 / 4$ depth saw cut in a chord in structure 4 produced a greater effect than $1 / 2$ depth cuts in structures 1 and 3 was resolved on the discovery that in addition to the deliberate damage, structure 4 had been accidentally dropped, resulting in a delamination of the fibres at one of the end brace to chord connection and reduction in the flexural stiffness of the bobbin mounting at one end. 


\section{Changes from baseline values}

If defects are to be detected in production batches of GRP structures the resulting frequency changes must exceed variations attributable to variable testing conditions and production tolerances in materials and construction. Each frequency measured must be compared with the expected value, as determined from baseline measurements, taking into account the degree of variation seen across a batch of good structures.

Using baseline data, different criteria can be established for judging whether or not a structure is damaged, and four examples are given in Table 4. These criteria judge the changes in frequency for the eight modes in each structure against the spread of values for the same mode across different structures and for repeated measurements.

Criteria 1 and 2 identify a structure as defective only if changes are measured in one or more parameters which are greater than the variation in these parameters observed across a batch of good structures. In contrast criteria 3 and 4 identify a structure as defective if changes are reliably detected from baseline measurements obtained on the same structure. These last two criteria will therefore identify smaller defects, but can only be applied in in-service tests when baseline measurements for each structure before service are available.

Comparison of the above results with Table 1 shows that some types of damage do not cause significant frequency changes; for structures $8,9,10$ and 11 the 'damage' is unlikely seriously to affect the performance of the structure. The damage in structure 1 differed from that in structure 3 only in its location so it is surprising that it was not readily detected. Studies in damage location ${ }^{14}$ using this data have clearly identified and located the damage in structure 1.

In practice criterion 1 could be used in a simple computer program together with baseline data and frequencies picked out on a spectrum analyser by an operator to judge damage. The process could be further automated using pattern recognition techniques to pick out resonances and to recognise frequency changes that do not follow the relatively uniform pattern of changes caused by, for example, variations in temperature.

\section{NONDESTRUCTIVE TESTING BY MEASURING MODE SHAPES}

The disadvantages of using measurements of changes in natural frequencies to detect damage in production batches of a structure are that the changes may be obscured by experimental inaccuracies and that the mean and variation of values of natural frequencies in undamaged structures must be known; the greater is this variation the

greater will be the frequency changes needed before damage can reliably be identified. 
Studies on a model structure representing a steel jacket for an offshore installation have shown ${ }^{15}$ that changes in mode shapes due to damage may be more significant than changes in frequencies. The changes in mode shape were characterised by the 'skewness' of translational vibrations as determined from the signals $A 1, A 2$ from two accelerometers A1, A2 positioned equidistant from an assumed line of symmetry and aligned in the plane of vibration. $A 1$ and $A 2$ would be identical unless uneven mass or stiffness distribution introduced a torsional effect. Different forms of damage might have a similar effect, and the ratio of the sum and difference of combinations of $A 1$ and $A 2$, defined as the 'skew ratio' and given by $(A 1-A 2) /(A 1+A 2)$, showed very large changes for the removal of a brace member, while natural frequencies showed only modest changes.

The same principle was expected to apply to the GRP structures, with the benefit that by the reasonable assumption (backed up by computer simulations ${ }^{\mathbf{1 4}}$ and the structural symmetry) of a zero skew ratio in an undamaged structure, no prior or 'baseline' measurements would be necessary.

\section{MEASUREMENT OF SKEW RATIOS FOR DAMAGED GRP BEAM MODE SHAPES}

The principle described above was applied to the GRP structures in a series of tests using a pair of operational amplifiers to add and subtract transient response signals $A 1$ and $A 2$ from two accelerometers $\mathrm{A} 1$ and $\mathrm{A} 2$ mounted in parallel on a GRP structure, as shown in Fig. 2. The results for flexural modes are given as the skew ratio $(A 1-A 2) /(A 1+A 2)$ and for torsional modes as $(A 1+A 2) /(A 1-A 2)$. In a good structure these differently defined skew ratios should be zero for the respective modes. The acceleration values $A 1$ and $A 2$ are defined as the values of auto power spectrum at resonance for each mode, read from a spectrum analyser.

In order to ensure identical acceleration signals for the same (translational) acceleration the accelerometer calibration values were closely matched by mounting $\mathrm{A} 1$ and $\mathrm{A} 2$ on a platform attached to a small shaker, comparing $A 1$ and $A 2$ on a two channel oscilloscope and adjusting the gain to minimise the difference signal $A 1-A 2$. At best, the difference signal was about $2 \%$ of, and $90^{\circ}$ out of phase with, the sum signal, and so experimental values of skew ratio less than $5 \%$ were considered as being sufficiently close to zero for all practical purposes.

Skew ratios for flexural modes in both planes were measured from an average of three hammer taps at $\mathrm{H} 2$ (Fig. 2), and for torsional modes the ratios were obtained from measurements in both planes by tapping at $\mathrm{H} 3$ at an angle of $45^{\circ}$ to the bracing. The ratios were determined for measurements at both ends A,B of each beam. Table 5 shows these ratios obtained from measurements of flexural and torsional modes at 
both ends of each of the 12 structures. The values for torsional modes are averaged over measurements in both planes.

The skew ratios were generally negligible for the lower flexural modes and increased significantly for higher modes, while torsional skew ratios did not show the same pattern.

In order for a quality control operator to be able to decide which structures are damaged, the volume of results such as presented in Table 5 needs to be condensed into some form of damage likelihood value. The simplest way to do this is to average the skew ratio values for all torsional modes, all flexural modes and all flexural and torsional modes. These average values are given in Table 6 .

Structures 1, 2 and 4 had the largest (total) values, followed by structures 7, 6, 8 and 12. The high value for structure 6 is curious bearing in mind that it was undamaged and suggests some degree of asymmetry in the (hand wound) structure. In contrast to the values obtained from frequency changes, structure 1 appeared to be the most damaged, while otherwise the methods are consistent.

\section{COMPARISON OF DAMAGE DETECTION TECHNIQUES}

The damage assessments based on frequency and mode shape ratios are compared in Table 7. This shows, for each structure, the type of damage and the extent of damage as assessed using the various criteria. Damage, assessed by the various criteria, is indicated by at least one ' $x$ '.

Damage indications in columns $\mathrm{i}$ to iv correspond directly to identification by the four criteria of Table 4.

Column $\mathbf{v}$ is based on the $\Sigma \Delta \mathrm{f}$ column of Table 3. Since the changed measurement conditions generally increased the frequency values, the summed frequency changes have a positive bias even for undamaged structures. To account for the bias, damage is indicated for negative values and large positive values, the latter also marked with an asterisk. Large negative values $(<-10)$, marked ' $x \times$ ', strongly indicate damage.

Column vi is based on the summed skew ratios from all modes (last column of Table 6). Values greater than 10 are indicated by ' $x$ ' and values greater than 20 by ' $x \times$ '.

Table 5 shows that there is consistency between the methods, although the damage in structure 1 is not easily detected.

In judging the success of the methods, the ease of making the assessment should be taken into account. The measurements of frequency change require attachment (by wax) of one accelerometer to two positions on each structure, and tapping at two positions for each accelerometer position. The frequency spectrum is displayed immediately, and the whole process takes about 30 seconds. The skew ratio method 
is a longer process, requiring the attachment of two accelerometers at one end of the structure and possibly repeating the test at the other end.

As well as being simpler to apply, the frequency change techniques were more successful in detecting damage, although the assessments shown in columns iii to $\mathrm{v}$ require knowledge of the undamaged (baseline) frequencies. Without knowledge of baseline values criteria $i$ and vi have similar degrees of success, although the reliance on symmetry in the skew ratio method of column vi may lead top erroneous identification of damage, such as in structure 6.

For both methods, the resonant frequencies need to be located and values read off (by hand or by transfer to a computer) and for skew ratios the amplitude values are also required. A computer algorithm using either the skew ratio or baseline frequency change methods would provide a damage assessment and, since the data required for the baseline frequency method is a subset of that required for the skew ratio method, assessment using both techniques could be provided at the same time.

Picking out resonant frequencies could be done in two ways:

1) The operator uses his own judgement to mark the peaks in each spectrum corresponding to the control frequencies (e.g. the 8 or 13 modes used in this study). These frequency values are then read onto a computer.

2) The entire spectrum is read onto a computer where signal processing such as that described in Reference 13 is used to identify the frequency peaks.

\section{CONCLUSIONS}

This study has described two techniques for assessing damage using measurements of dynamic properties. Both techniques showed a high success rate for the example structures and one or both of these would provide an effective method of quality control if combined with a simple visual check.

Damage such as completely or partially severed members generally caused the greatest changes in modal properties. Partial severance (e.g. cracking) can be difficult to detect visually but can considerably weaken the structure. The accidental damage sustained by one of the structures was only discovered as a result of the measurements, showing how effective the techniques can be.

Both methods rely on some knowledge of the normal (undamaged) modal behaviour and if the variations of this behaviour due to production tolerances can be minimised, the methods will be more effective.

Of the methods and assessment criteria, the method of comparing frequencies of production examples with those of a sample batch would be the most practical, and in the testing this method was successful at identifying most of the damaged structures. 
The information provided by the techniques described in this paper is limited to a qualitative indication of damage. It is possible to go a stage further and use a more complete description of the dynamic behaviour of the structure, derived from a validated mathematical (finite element) model to suggest the location as well as the magnitude of the damage. Techniques developed and described in Reference ${ }^{16}$ have been applied to the GRP structures and have shown some success in identifying and locating damage ${ }^{14}$. 


\section{FIGURES}

Figure 1 GRP structure no. 12 showing detail of chord, brace and bobbins.

Figure 2 Dimensions of GRP beam and arrangement for modal testing.

Figure 3 Acceleration auto power spectra for structure 7 at end B:

a) Tap at $\mathrm{H} 2$ (centre) measure at $\mathrm{A} 3$ (centre), flat plane

b) Tap at $\mathrm{H} 1$ (edge) measure at A1 (edge), flat plane

c) Tap at $\mathrm{H} 2$ (centre) measure at $\mathrm{A} 3$ (centre), side plane

d) Tap at $\mathrm{H} 1$ (edge) measure at A1 (edge), side plane

Figure 4 Modes shapes of GRP structure in cross-section

Figure 5 Computer-generated mode shapes for GRP structures

Figure 6 Natural frequencies for mode $2 \mathrm{~T}$ in structures 6-12 at three temperatures

\section{TABLES}

Table 1 Specifications and damage to GRP structures

Table 2 Scatter of frequency measurements on single structure and across a batch

Table 3 Measured frequency changes caused by damage in GRP structures

Table 4 Damage assessment criteria based on changes of natural frequencies

Table 5 Skew ratios for GRP structures

Table 6 Average skew ratios

Table 7 Comparison of vibration-based NDT techniques 


\section{REFERENCES}

1 R D Adams, P Cawley, 'Vibration techniques in non-destructive testing', Research Techniques in NDT, 1985, 8, pp. 304-360.

2 D M Lilley, R D Adams, W J Larnach, 'Location of defects within embedded model piles using a resonant vibration technique', 10th World Conference on Nondestructive Testing, Moscow, 1982, Paper 3-4, pp. 77-84.

3 P Cawley, 'Rapid production quality control by vibration measurements', Materials Evaluation. Vol. 45 May 1987, pp. 564-568.

4 C J Pye, R D Adams, 'Detection of damage in fibre reinforced plastic using thermal fields generated during resonant vibration', NDT International. Vol. 14 June 1981, pp. 111-118.

5 P Cawley, R D Adams, 'Sensitivity of the coin-tap method of Nondestructive testing', Materials Evaluation. Vol. 47 May 1989, pp. 558-563.

6 T A Brown, R D Milne, 'Strategies for the verification of a finite element model', 3rd International Modal Analysis Conference, Orlando, Florida, Jan. 1985.

7 M Richardson, 'Detection of damage in structures from changes in their dynamic (modal) properties - a survey', Report NUREG/CR-1431, US Nuclear Regulatory Commission Washington DC. NRC FIN AO128, April 1980.

8 P R Sparks, A P Jeary, V C M De Souza, 'A study of the use of ambient vibration measurements to detect changes in the structural characteristics of a building', Dynamic Response of Structures: Experimentation, Observation, Prediction and Control. ASCE EMD Specialty Conference, 15-16 Jan. 1981, Atlanta, Georgia.

9 H J Salane, J W Baldwin, 'Identification of modal properties of bridges', Journal of Structural Engineering, ASCE Vol 116 no. 7, July 1990, pp. 2008-2021.

$10 \mathrm{~J}$ K Vandiver, 'Detection of structural failure on fixed platforms by measurement of dynamic response', 7th Annual Offshore Technology Conference, Houston, Texas, 1975, pp. 243-252.

11 H A Cole, 'On-line failure detection and damping measurements of aerospace structures by random decrement signatures', NASA CR2205 Mar. 1973.

12 P Cawley, 'Non-destructive testing of mass produced components by natural frequency measurements', Proc. I. Mech. E, 1985 Vol. 199, No. B3, pp. 161-168.

13 J B Comerford, D I Blockley, J P Davis, 'The interpretation of measurements from Civil Engineering systems', Journal of Civil Engineering Systems 6(3) 1989. 
14 J M W Brownjohn, 'Assessment of structural integrity by dynamic measurements', PhD thesis, University of Bristol Department of Civil Engineering, April 1988.

15 F Shahrivar, J G Bouwkamp, 'Damage detection in offshore platforms using vibration information' $3 r d$ Offshore Mechanics and Arctic Engineering Symposium, Vol. 2, New Orleans, Louisiana, 1980 (ASME), pp. 174-185.

16 P Cawley, R D Adams, 'The location of defects in structures from measurements of natural frequencies', Journal of Strain Analysis Vol. 14 no. 2 1979, pp. 49-57. 
Table 1 Specifications and damage to GRP structures

\begin{tabular}{|c|c|c|c|c|c|}
\hline structure & wound by & $\begin{array}{l}\text { bobbin } \\
\text { metal }\end{array}$ & $\begin{array}{l}\text { weight } \\
/ \mathrm{kg}\end{array}$ & damage at ${ }^{*}$ & description of damage \\
\hline 1 & machine & steel & 4.935 & 4,20 & $\begin{array}{l}\text { saw cuts halfway through (axial) } \\
\text { chord member }\end{array}$ \\
\hline 2 & machine & steel & 4.86 & 12,27 & section of chord removed \\
\hline 3 & machine & aluminium & 4.65 & 2,24 & $\begin{array}{l}\text { saw cuts halfway through chord } \\
\text { member }\end{array}$ \\
\hline 4 & machine & steel & 5.1 & 4,20 & $\begin{array}{l}\text { saw cuts quarter-way through } \\
\text { chord member }\end{array}$ \\
\hline 5 & machine & aluminium & 4.41 & - & no damage \\
\hline 6 & hand & aluminium & 4.8 & - & no damage \\
\hline 7 & hand & aluminium & 4.81 & 4,20 & brace member removed \\
\hline 8 & hand & aluminium & 4.825 & 5,20 & $\begin{array}{l}\text { chord member severed and } \\
\text { repaired with resin and glass }\end{array}$ \\
\hline 9 & hand & aluminium & 4.75 & $4-5,19-20$ & chord/brace junctions burnt \\
\hline 10 & hand & aluminium & 4.78 & 5,21 & chord abraded with file \\
\hline 11 & hand & aluminium & 4.75 & $5-6,20-21$ & $\begin{array}{l}\text { multiple impacts on chord/brace } \\
\text { junction }\end{array}$ \\
\hline 12 & hand & aluminium & 4.75 & 1 & crushing at end \\
\hline
\end{tabular}

*The numbers correspond to the $100 \mathrm{~mm}$ long brace section; 1 is end $\mathrm{A}, 30$ is end $\mathrm{B}$ 
Table 2 Consistency of frequency measurements on single structure and across batch

\begin{tabular}{|l|l|l|l|}
\hline mode & $\begin{array}{l}\text { \% variation in structure 7 } \\
\text { over four measurements }\end{array}$ & $\begin{array}{l}\text { Mean value of natural } \\
\text { frequency/Hz, structures 6-12 }\end{array}$ & $\begin{array}{l}\text { Largest \% difference from } \\
\text { mean of batch, structures 6-12 }\end{array}$ \\
\hline 1FF & 0.4 & 61.61 & 1.4 \\
\hline 2FF & - & 158.04 & 1.1 \\
\hline 3FF & - & 282.5 & 6.1 \\
\hline 4FF & 0.6 & 379.66 & 1.6 \\
\hline 5FF & 0.3 & 463.59 & 1.6 \\
\hline 1FS & 0.8 & 61.36 & 1.5 \\
\hline 2FS & - & 158.4 & 0.9 \\
\hline $3 \mathrm{FS}$ & - & 284.92 & 0.9 \\
\hline 4FS & 0.1 & 416.79 & 0.8 \\
\hline 2T & 0 & 342.83 & 0.5 \\
\hline $3 \mathrm{~T}$ & 0.1 & 500.19 & 0.6 \\
\hline $5 \mathrm{NB}$ & 0.3 & 404.46 & 0.7 \\
\hline $6 \mathrm{NB}$ & - & 517.5 & 0.7 \\
\hline
\end{tabular}


Table 3 Measured frequency changes caused by damage in GRP structures

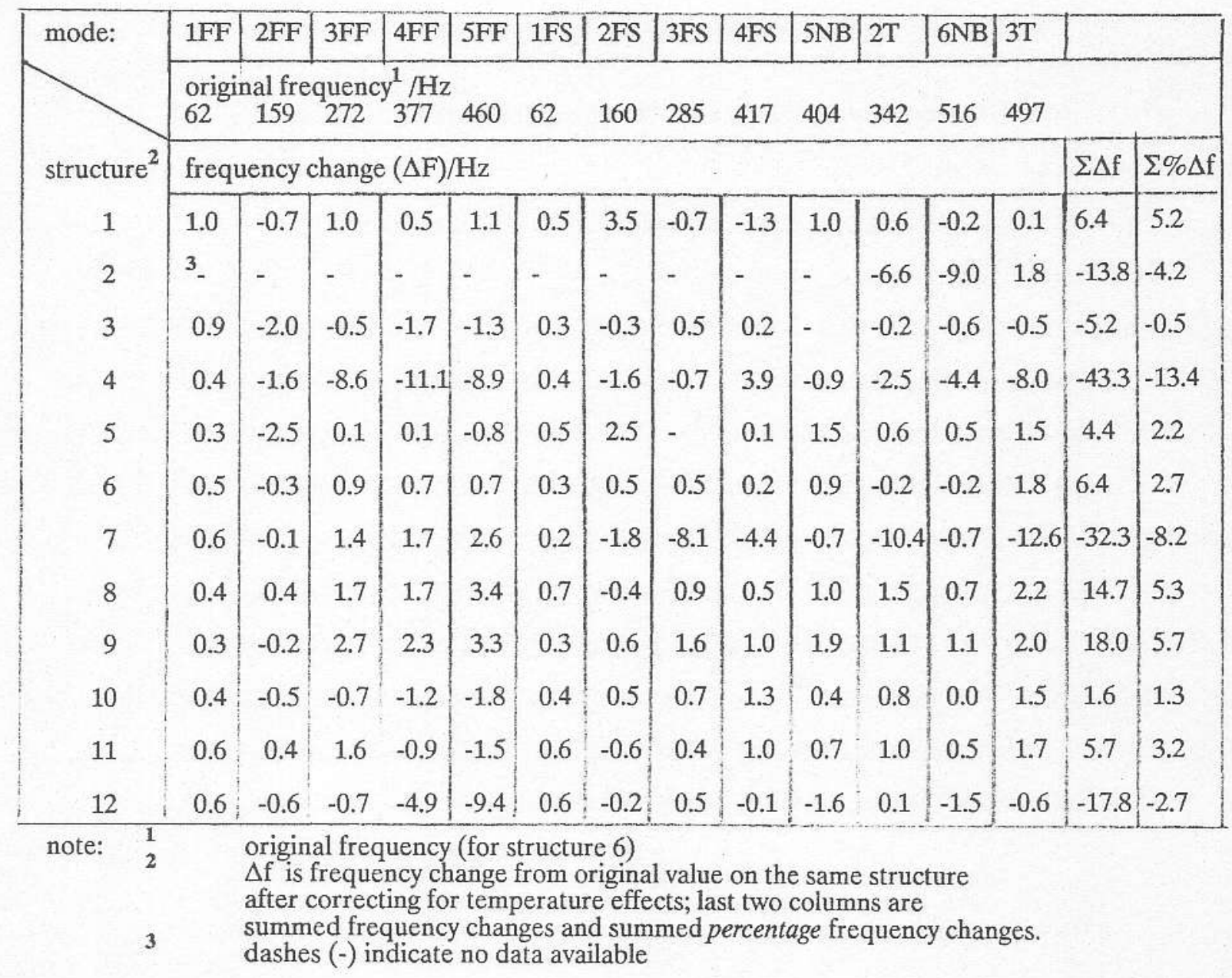




\begin{tabular}{|c|c|c|}
\hline$\#$ & criterion applied to indicate damage & $\begin{array}{l}\text { structures identified } \\
\text { as damaged }\end{array}$ \\
\hline 1 & $\begin{array}{l}\text { At least one natural frequency in the structure shows a } \\
\text { change greater than the variation of that frequency } \\
\text { across the batch of structures before damage: }\end{array}$ & $2,3,4,7,12$ \\
\hline 2 & As 1 , but for at least two modes: & $2,3,4,7$ \\
\hline 3 & $\begin{array}{l}\text { At least one natural frequency in the structure shows a } \\
\text { change greater than the variation of that frequency for } \\
\text { repeated measurements in a typical structure: }\end{array}$ & $\begin{array}{l}1,2,3,4,6,7,10 \\
11,12\end{array}$ \\
\hline 4 & As 3, but for at least two modes: & $2,3,4,7,12$ \\
\hline
\end{tabular}


Table 5 Skew ratios for GRP structures

\begin{tabular}{|c|c|c|c|c|c|c|c|c|c|c|c|c|}
\hline mode: & $1 \mathrm{FF}$ & $2 \mathrm{FF}$ & $3 \mathrm{FF}$ & $4 \mathrm{FF}$ & $5 F F$ & 1FS & $2 \mathrm{FS}$ & $3 F S$ & $4 \mathrm{FS}$ & $1 \mathrm{~T}$ & $2 \mathrm{~T}$ & $3 \mathrm{~T}$ \\
\hline structure, end & \multicolumn{12}{|c|}{$\%$ skew ratio 1,2} \\
\hline $1 \mathrm{~A}$ & 2 & 16 & 5 & 240 & 218 & 3 & 1 & 18 & 13 & 22 & 5 & 410 \\
\hline $1 \mathrm{~B}$ & 2 & 3 & 1 & 19 & 129 & 2 & 7 & 24 & 16 & 231 & 91 & 97 \\
\hline $2 \mathrm{~A}$ & 1 & 10 & - & 36 & 31 & 1 & 32 & 79 & - & 24 & 10 & 154 \\
\hline $2 B$ & 1 & 11 & - & 21 & 111 & 6 & 2 & 69 & - & 14 & 15 & 56 \\
\hline $3 \mathrm{~A}$ & 1 & 1 & 8 & 16 & 30 & 2 & 8 & 27 & 19 & -1 & 73 & 14 \\
\hline $3 \mathrm{~B}$ & 1. & 2 & 5 & 11 & 22 & 4 & 3 & 33 & 7 & - & 23 & 24 \\
\hline $4 \mathrm{~A}$ & 2 & 2 & 7 & 72 & 61 & 2 & 29 & 12 & 50 & 8 & 29 & 24 \\
\hline $4 B$ & 1. & 4 & 27 & 97 & 263 & 3 & 16 & 49 & 12 & 23 & 28 & 34 \\
\hline $5 \mathrm{~A}$ & 2 & 2 & 1 & 3 & 18 & 1 & 24 & 28 & 5 & - & 8 & - \\
\hline $5 B$ & 1 & 5 & 2 & 5 & 3 & 2 & 3 & 27 & 5 & - & 4 & - \\
\hline $6 \mathrm{~A}$ & 2 & 2 & 8 & 2 & 6 & 2 & 4 & 9 & 4 & 10 & 76 & \\
\hline $6 \mathrm{~B}$ & 3 & 6 & 19 & 32 & 61 & 3 & 1 & 1 & 9 & 27 & 35 & 23 \\
\hline $7 \mathrm{~A}$ & 2 & 3) & 6 & 3 & 3 & 2 & 24 & 4 & 2 & 35 & 48 & 40 \\
\hline $7 B$ & 1 & 6 & 14 & 31 & 58 & 2 & 16 & 14 & 5 & 30 & 38 & 18 \\
\hline $8 \mathrm{~A}$ & 2 & 2 & 5 & 10 & 14 & 2 & 2 & 6 & 2 & 20 & 82 & 18 \\
\hline $8 \mathrm{~B}$ & 3 & 2 & 5 & 20 & 52 & 2 & 2 & 1 & 4 & 40 & 35 & 7 \\
\hline $9 \mathrm{~A}$ & 3 & 4 & 0 & 3 & 5 & 1 & 3 & 4 & 14 & 10 & 27 & 11 \\
\hline $9 \mathrm{~B}$ & 2 & 4 & 12 & 30 & 38 & 1 & 5 & 5 & 9 & 7 & 13 & 7 \\
\hline $10 \mathrm{~A}$ & 4 & 7 & 17 & 23 & 36 & 1 & 3 & 1 & 3 & 11 & 3 & 5 \\
\hline $10 \mathrm{~B}$ & 3 & 1 & 5 & 5 & 10 & 1 & 1 & 2 & 5 & 17 & 7 & 11 \\
\hline $11 \mathrm{~A}$ & 1 & 3 & 11 & 15 & 22 & 1 & 3 & 5 & 3 & 14 & 5 & 7 \\
\hline $11 B$ & 2 & 2 & 1 & 5 & 3 & 1 & 1 & 2 & 6 & 10 & 4 & 7 \\
\hline $12 \mathrm{~A}$ & 1 & 3. & 6 & 10 & 22 & 1 & 1 & 1 & 4 & 12 & 25 & 17 \\
\hline $12 B$ & 1 & 6 & 21 & 37 & 65 & 1 & 1 & 1 & 2 & 23 & 22 & 19 \\
\hline
\end{tabular}

note: $\quad 1 \quad$ Skew values for flexural modes $\mathrm{S}_{\mathrm{f}}$ are $100^{*}(A 1-A 2) /(A 1+A 2)$.

Skew values for torsional modes $\mathrm{S}_{\mathrm{t}}$ are $100^{*}(A 1+A 2) /(A 1-A 2)$

and are averaged over two measurements (in flat and side planes)

Dashes (-) indicate no data available. 
Table 6 Average skew ratios

\begin{tabular}{|l|l|l|l|}
\hline Structure & $\begin{array}{l}\text { Mean of skew ratios } \\
\text { for flexural modes }\end{array}$ & $\begin{array}{l}\text { Mean of skew ratios } \\
\text { for torsional modes }\end{array}$ & $\begin{array}{l}\text { Mean of skew ratios } \\
\text { for all modes }\end{array}$ \\
\hline 1 & 40.0 & 66.6 & 50.1 \\
\hline 2 & 29.4 & 45.6 & 36.8 \\
\hline 3 & 11.1 & 17.0 & 12.9 \\
\hline 4 & 39.4 & 25.9 & 33.3 \\
\hline 5 & 8.9 & 6.0 & 8.3 \\
\hline 6 & 9.7 & 29.5 & 17.6 \\
\hline 7 & 10.9 & 35.0 & 20.5 \\
\hline 8 & 7.6 & 26.2 & 15.0 \\
\hline 9 & 7.9 & 12.8 & 9.9 \\
\hline 10 & 5.6 & 9.5 & 8.0 \\
\hline 11 & 4.8 & 7.8 & 5.6 \\
\hline 12 & 10.2 & 19.9 & 14.1 \\
\hline 1 & $\begin{array}{l}\text { skew ratio for flexural modes }= \\
\text { skew ratio for torsional modes }=\end{array}$ & $100^{*}(A 1-A 2) /(A 1+A 2) /(A 1-A 2)$ & \\
\hline
\end{tabular}




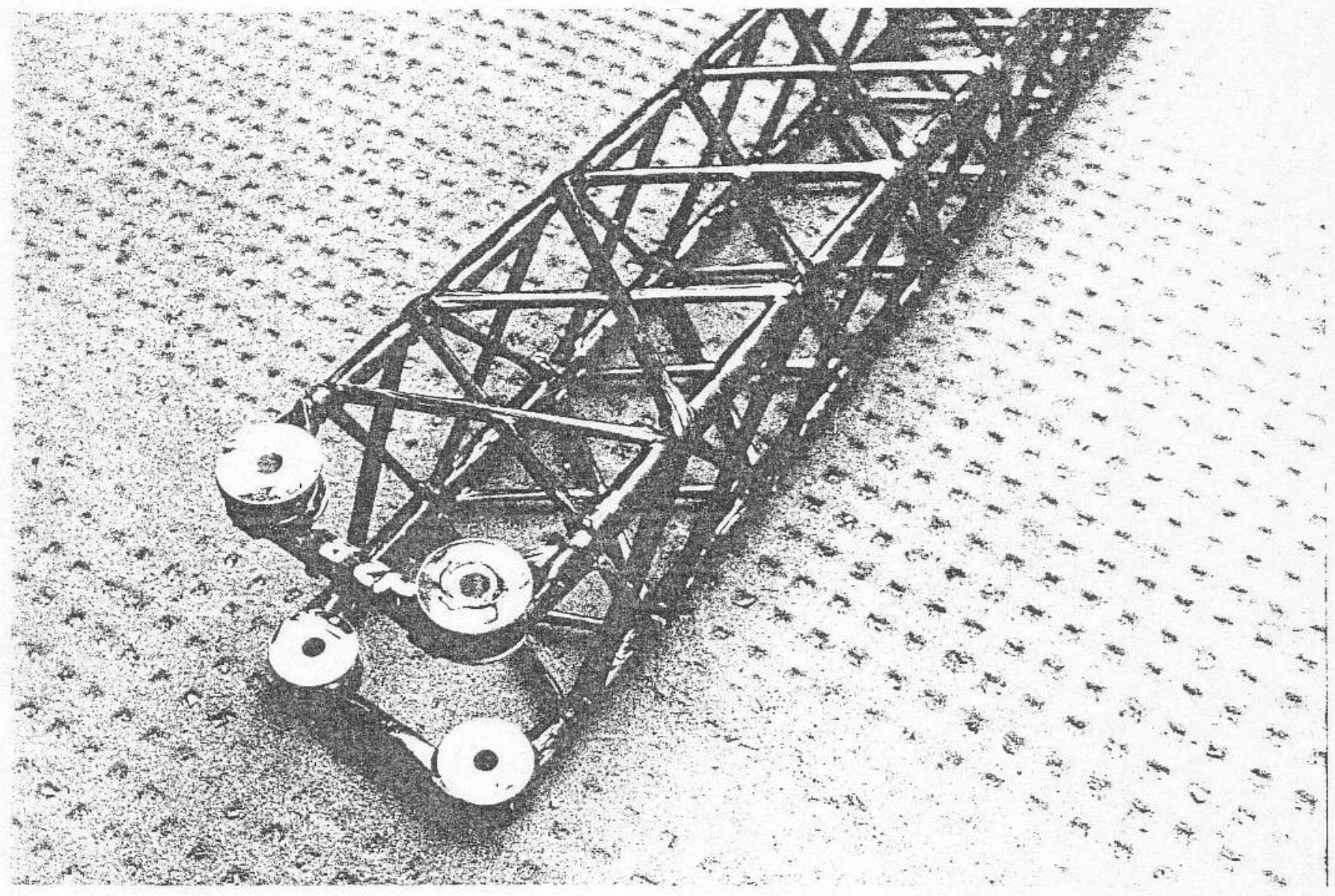

Figure 1 GRP structure no. 12 showing detail of chords, braces and bobbins 

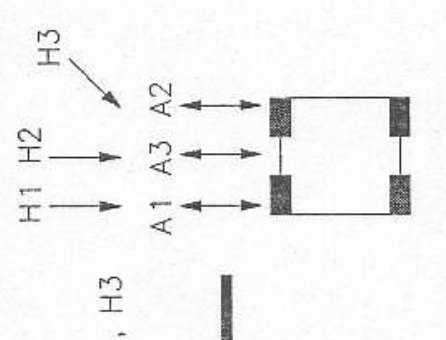

I

I
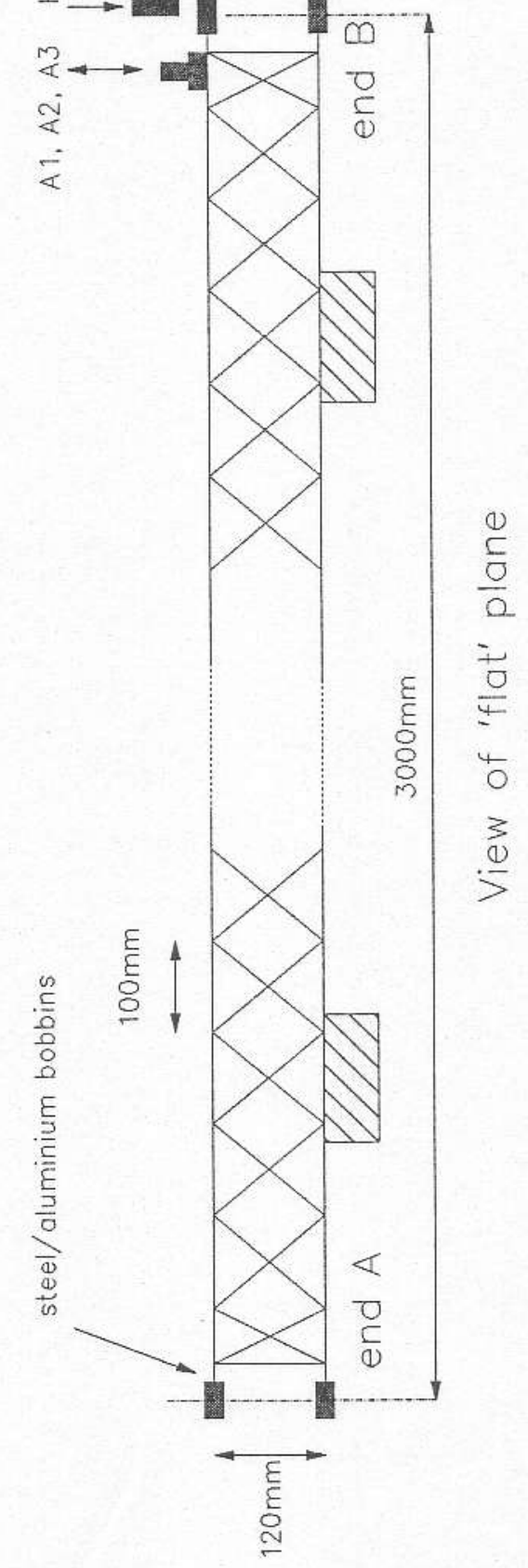
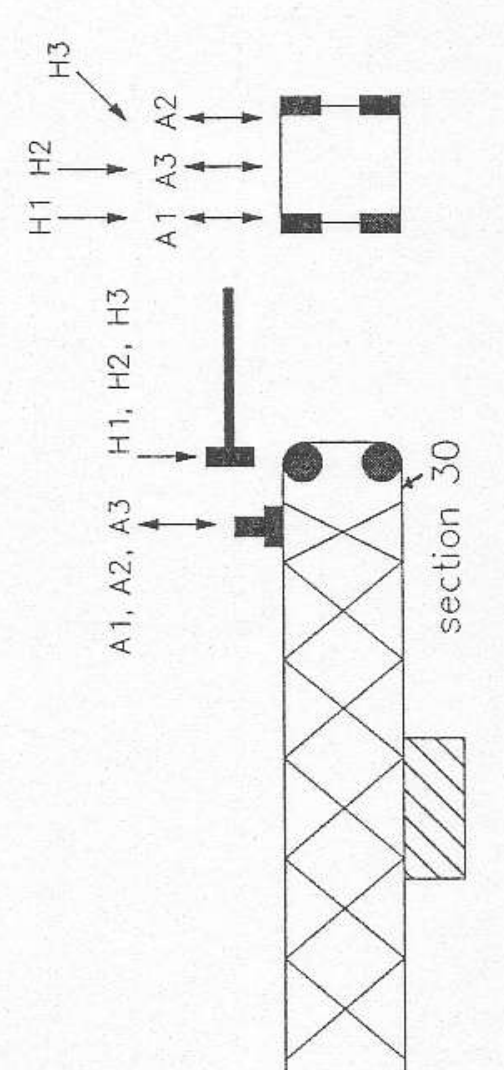

$\frac{1}{5}$
$\frac{0}{0}$
$\frac{1}{0}$
$\frac{0}{4}$
4
0
3
3
3

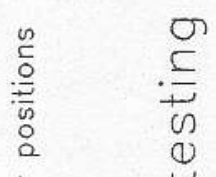

迹告

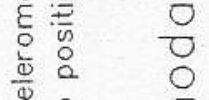

岕衣 है

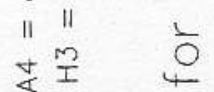

胥采

立定

(1) $\frac{a}{0}$

$\frac{5}{0} \quad 4$

$\frac{D}{0} \quad \frac{0}{0}$

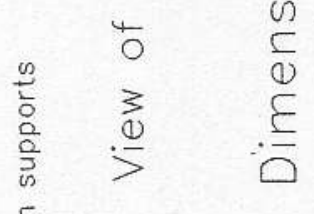

N

iั 


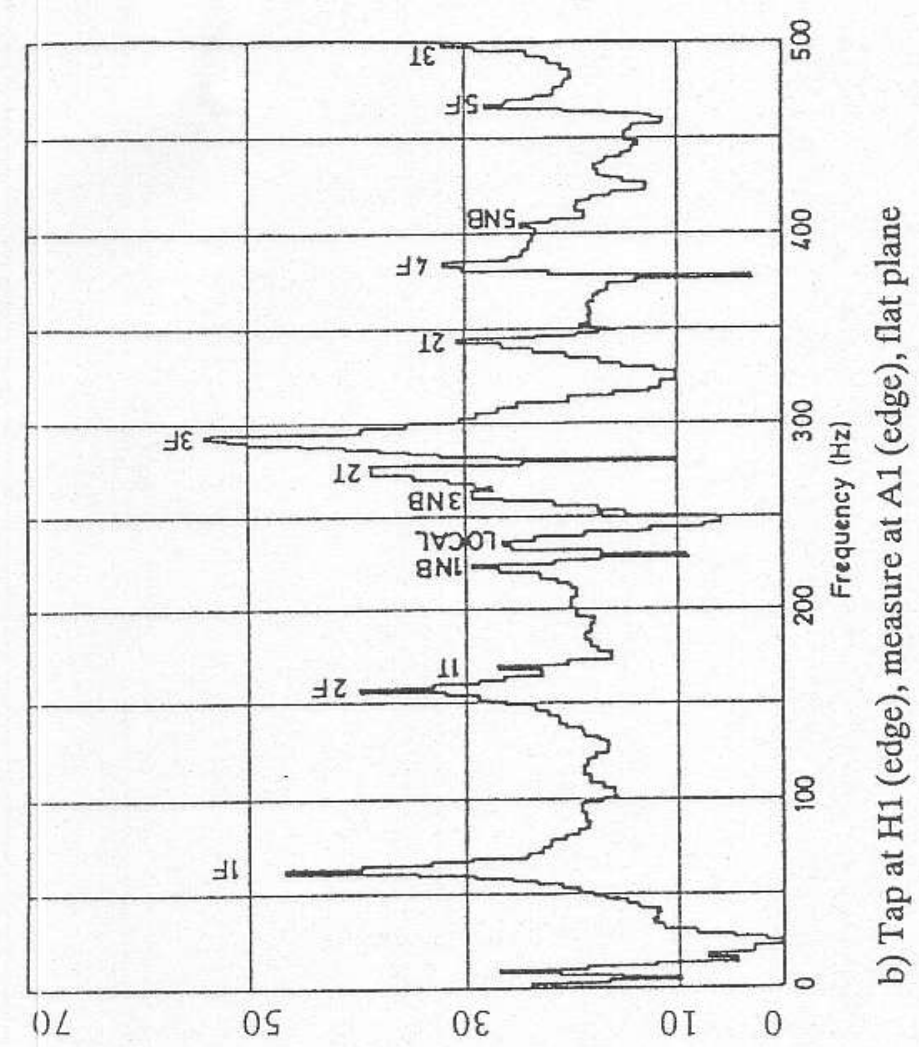

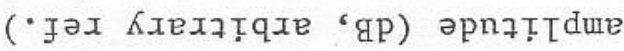

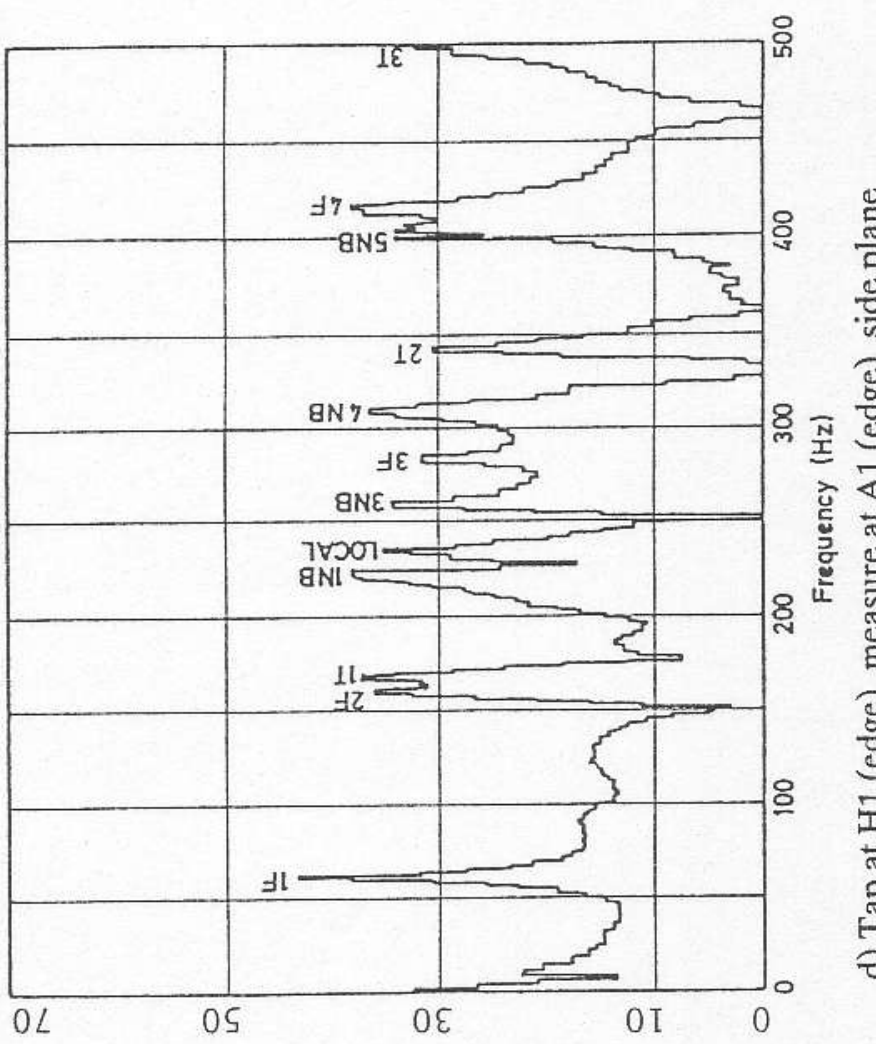

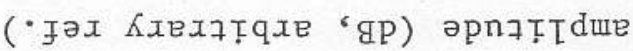

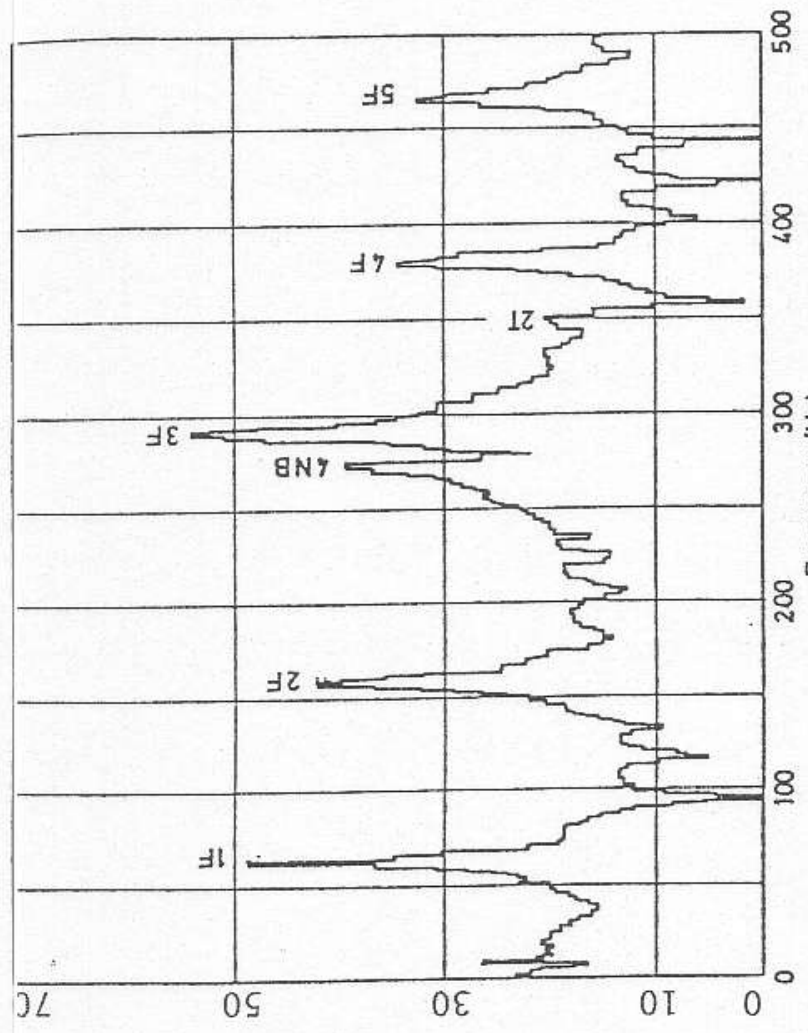

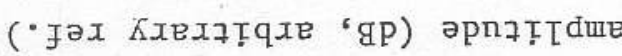

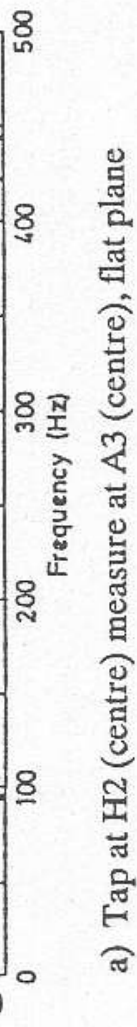

$0 L$

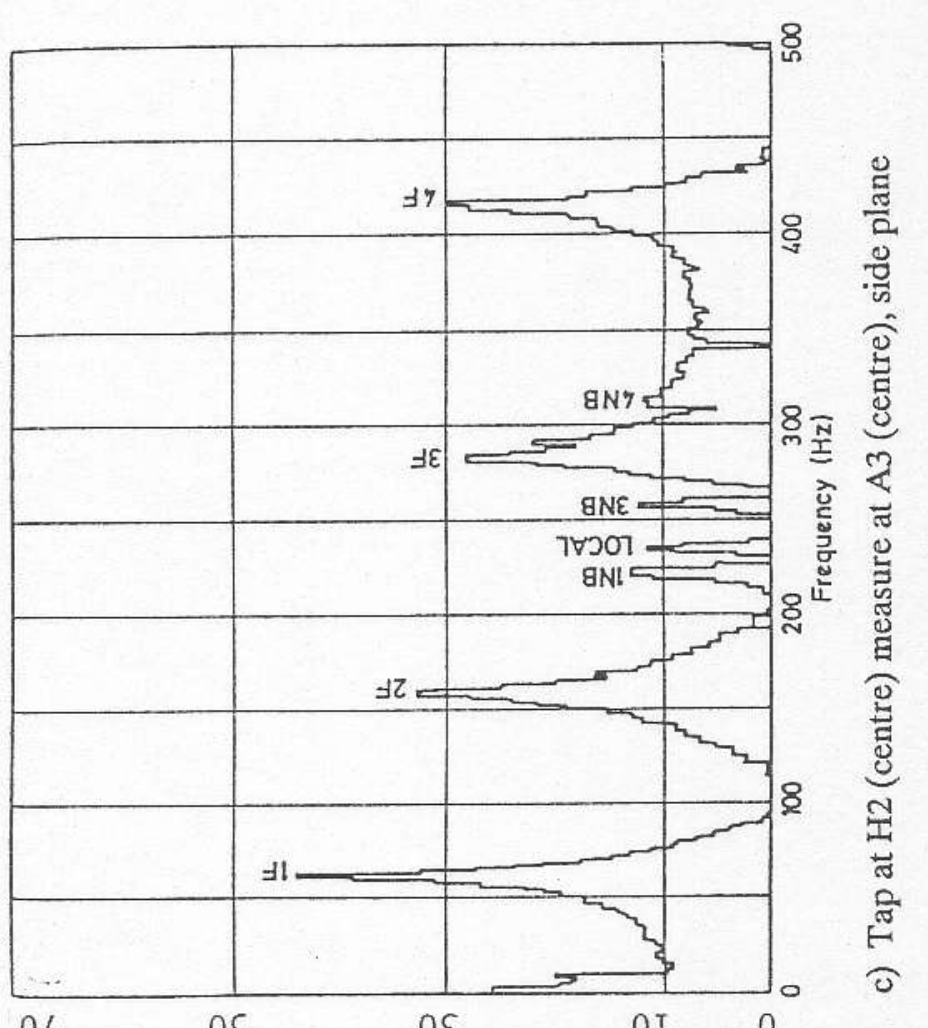

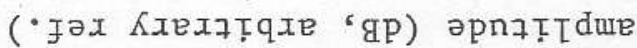



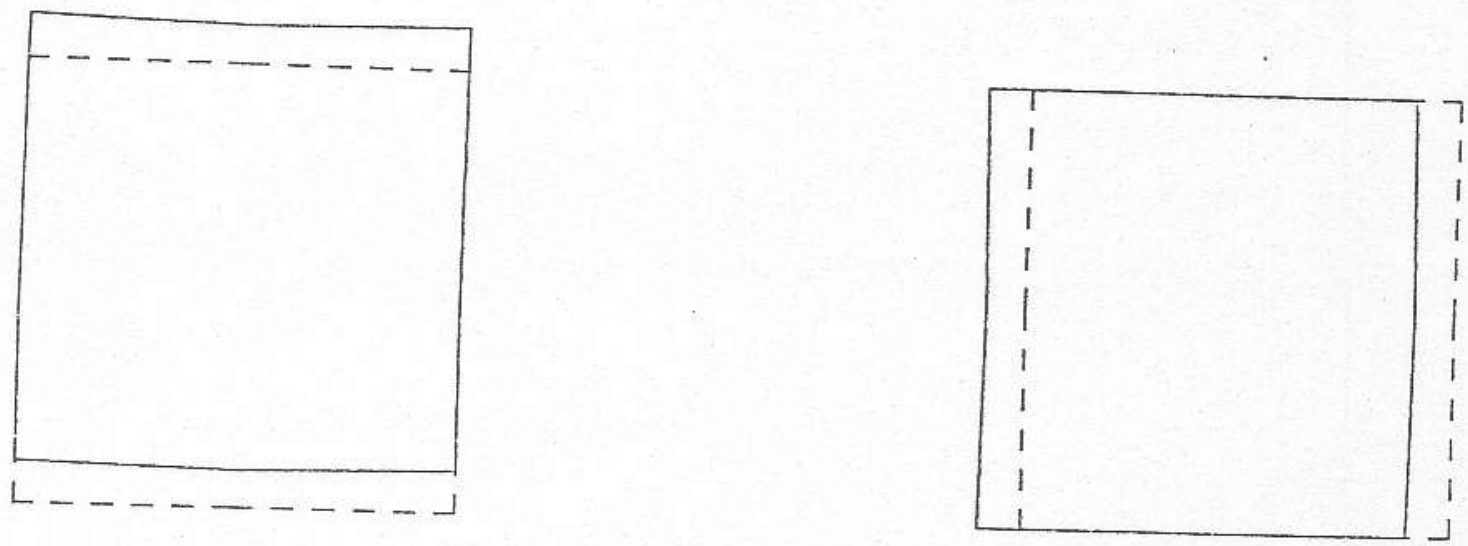

Flexural Flat modes:

1FF 2FF 3FF 4FF 5FF

$\begin{array}{lllll}62.1 & 159.1 & 271.7 & 377 & 599.6 \mathrm{~Hz}\end{array}$
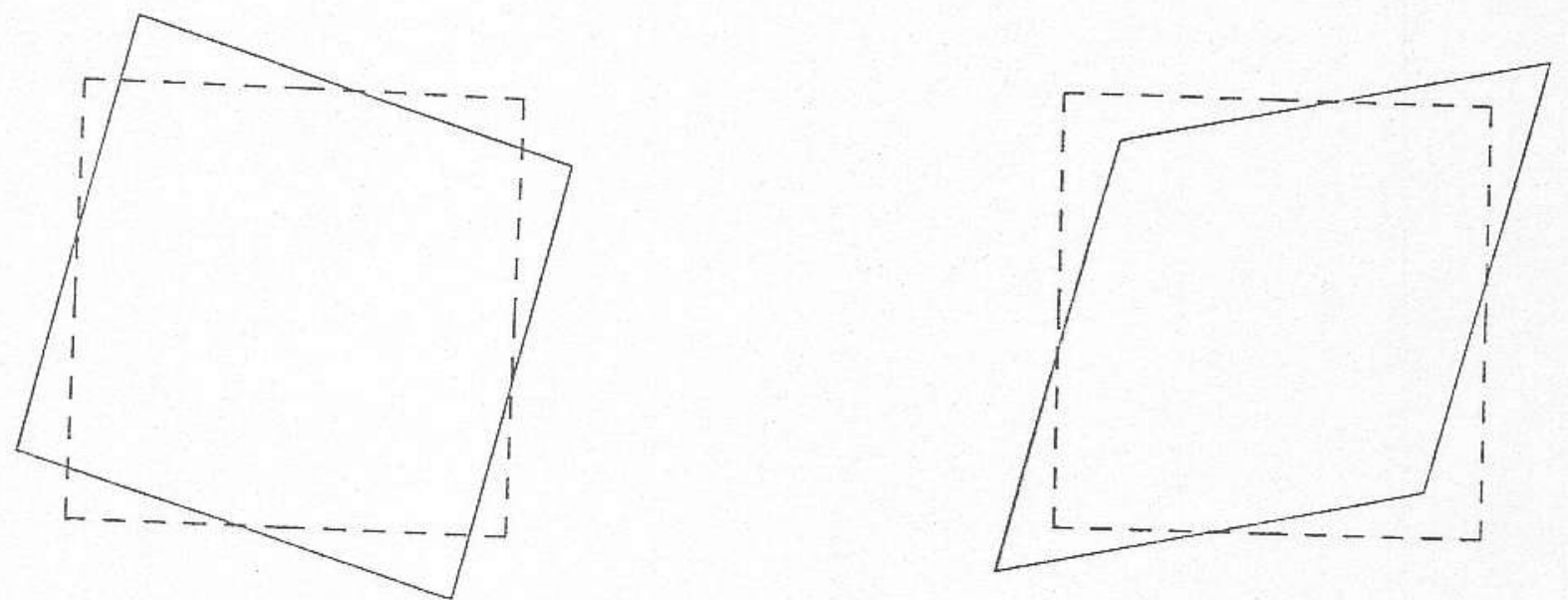

Torsional modes :

$\begin{array}{lll}1 \mathrm{~T} & 2 \mathrm{~T} & 3 \mathrm{~T} \\ 166 & 341.6 & 497.3 \mathrm{~Hz}\end{array}$

Breathing modes :

$0 \mathrm{NB} \quad 1 \mathrm{NB} \quad 3 \mathrm{NB} \quad 4 \mathrm{NB} \quad 5 \mathrm{NB} \quad 6 \mathrm{NB}$ $\begin{array}{llllll}208 & 238 & 257 & 308 & 404.1 & 516 \mathrm{~Hz}\end{array}$

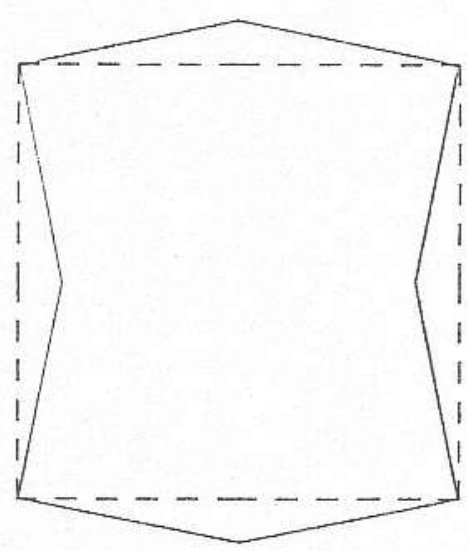

' $\mathrm{X}$ ' modes (see text) 1FS 2FS 3FS 4FS $\begin{array}{llll}61.5 & 159.6 & 285.4 & 417.5 \mathrm{~Hz}\end{array}$

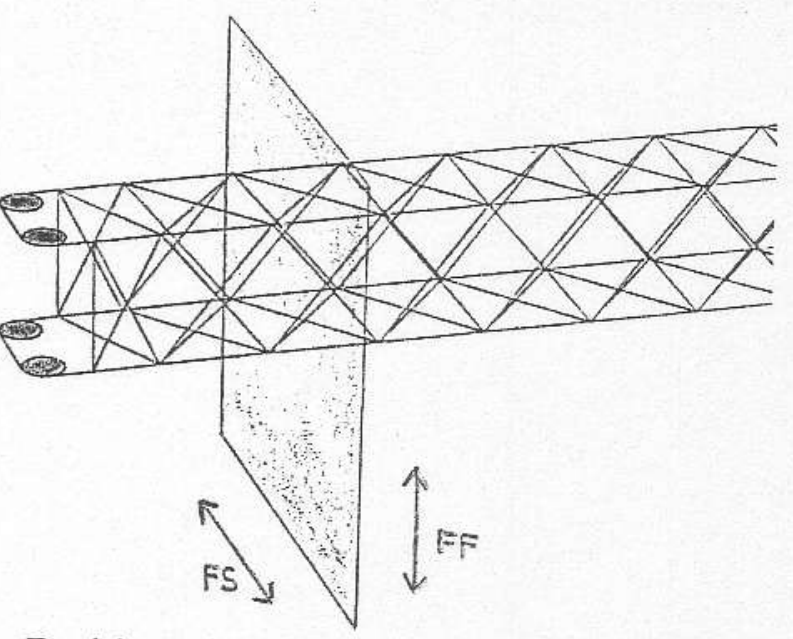

Position of cross-section

Fig. 4 Mode shapes of GRP structure in cross section.

Frequencies are for structure 6 


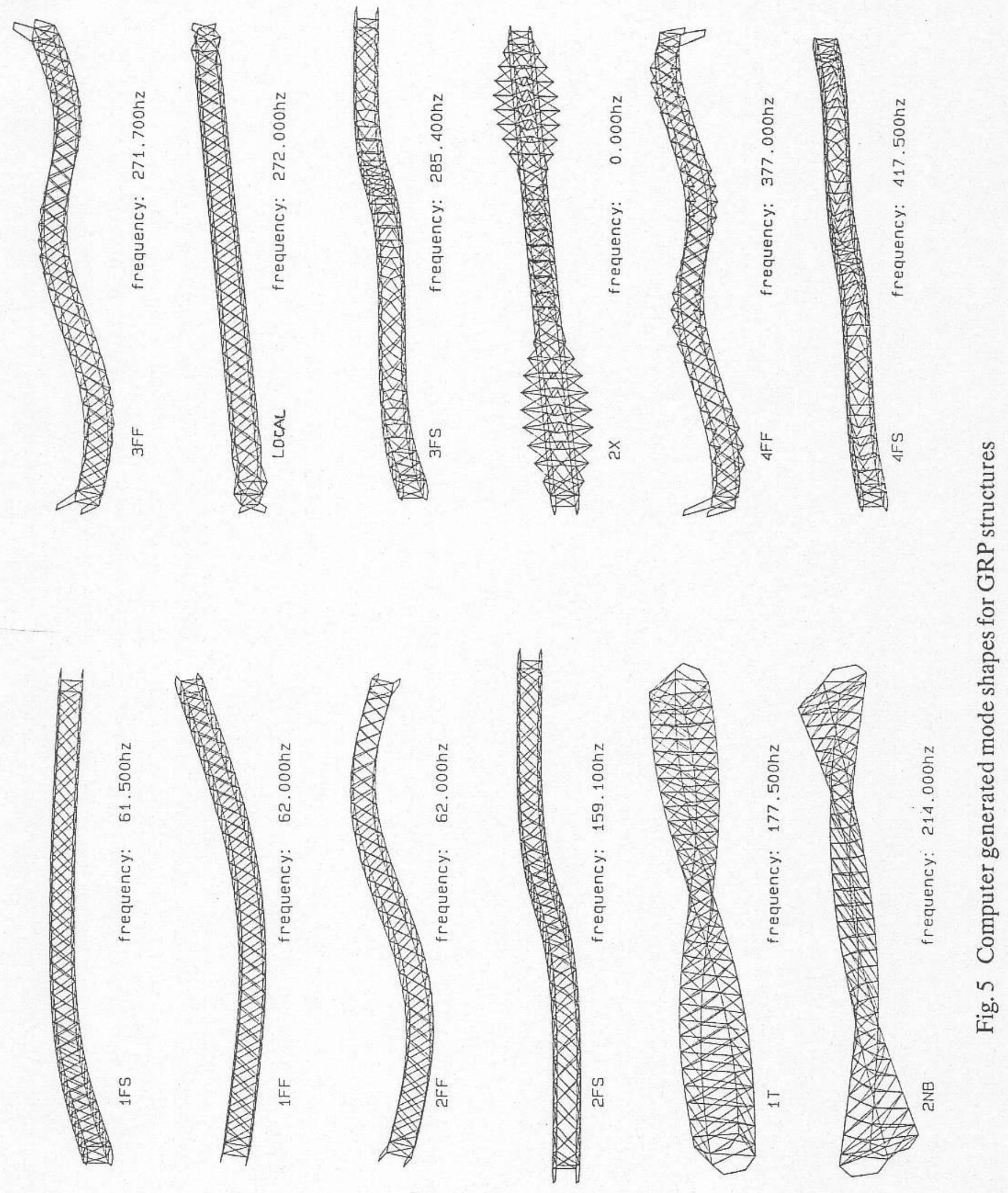




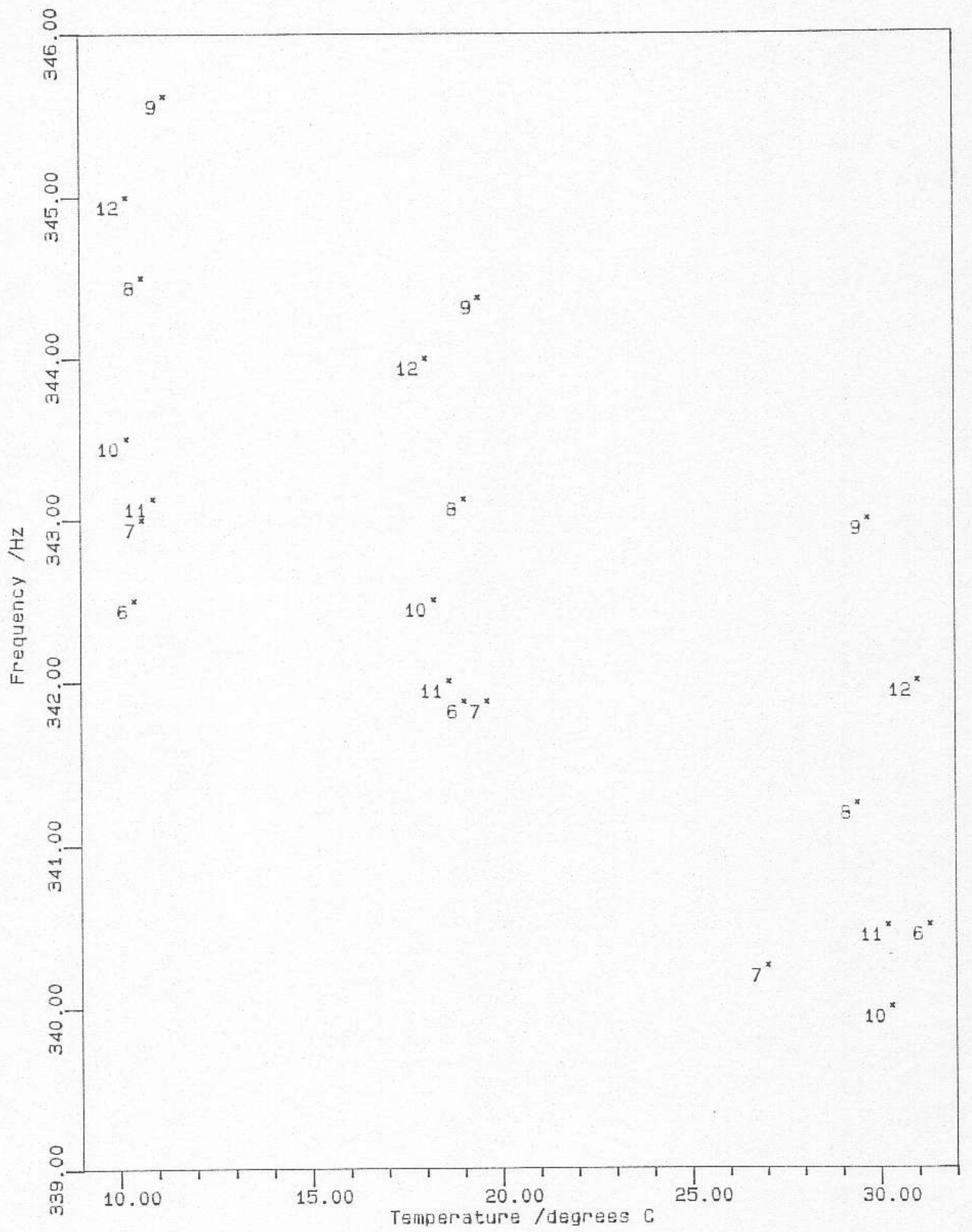

Fig. 6 Natural frequencies for mode $2 \mathrm{~T}$ in structures 6-12 at three temperatures 